\title{
The Effects of Paravertebral Bupivacaine-Dexmedetomidine Versus Bupivacaine-Fentanyl in Unilateral Open Renal Surgeries
}

\author{
Reem Abdelraouf Elsharkawy ${ }^{1 *}$, Mohamed Nashaat Mohamed ${ }^{1}$, Gamal Mohamed Zakari ${ }^{1}$ and \\ Mahmoud Mahmoud Othman ${ }^{1}$ \\ ${ }^{1}$ Department of Anesthesia and Intensive Care, Mansoura University, Egypt.
}

Received: November 06 2017; Accepted: July 31 2018; Published: September 042018

*Corresponding author: Reem Abdelraouf Elsharkawy, Faculty of Medicine, Department of Anesthesia and Intensive Care, Mansoura University, Egypt. Tel: +050 2235096; Fax: +2 0502267016; E-mail: reemraouf64@gmail.com

\begin{abstract}
Study Objective: This trial was designed to test the benefits of adding dexmedetomidine to bupivacaine if compared with the bupivacaine- fentanyl mixture in paravertebral block for different renal surgeries.
\end{abstract}

Design: Prospective randomized and double-blinded study.

Setting: Operative room and postoperative recovery area.

Patients: Fifty patients, ASA physical status I and II, aged above 20 years, scheduled for elective open unilateral renal surgeries (nephrectomy, pyelolithotomy and pyeloplasty).

Intervention: Patients were randomly allocated by the computer generated list into 2 equal groups (each group had 25patient). Bupivacaine - dexmedetomidine (BD) group received paravertebral bupivacaine $0.2 \%+$ dexmedetomidine $1 \mu / \mathrm{kg}$ for patient below 65 years and $0.5 \mu / \mathrm{kg}$ for patient above 65 years in a total volume of 20 $\mathrm{ml}$.

Bupivacaine - fentanyl (BF) group received paravertebral bupivacaine $0.2 \%+$ fentanyl $1 \mu / \mathrm{kg}$ for patient below 65 years and fentanyl $0.5 \mu / \mathrm{kg}$ for patient above 65 years in a total volume of $20 \mathrm{ml}$

Measurements: Pain assessed by VAS, heart rate, mean arterial blood pressure, Spo2, postoperative sedation, postoperative adverse effects, total requirement of opioid and first request for analgesia.

Main Results: Post-operative visual analogue score and postoperative sedation score were significantly different between both groups in favor of BD group.

No satistical difference between both groups as regard HR mean blood pressure and oxygen saturation. No postoperative adverse effects were recorded.

Conclusions: The addition of dexmedetomidine to bupivacaine in paravertebral block provides prolonged postoperative analgesia and better sedation score. Also, the addition of dexmedetomidine leads to a reduction in the usage of postoperative opioid.

Keywords: Dexmedetomidine; Paravertebral block; unilatera open renal surgery;

\section{Introduction}

Postoperative analgesia following renal surgeries is mandatory to allow early mobilization of the patients, effective coughing, shorten the hospital stay and to reduce the incidence of respiratory complications [1]. A variety of techniques had been used to control this type of pain including intravenous or intramuscular injection of paracetamol or nonsteriod antiinflammatory drugs or epidural analgesia [2].

Recently, Paravertebral Block (PVB) had been utilized in many surgical procedures (abdominal, thoracic, or pelvic) both as a primary anesthetic technique and as postoperative analgesia [3]. However; few studies had been done using PVB in urological surgeries. Some of these studies used PVB as a proper anesthetic tool for patients underwent lithotripsy ,microwave ablation of kidney tumors or percutaneous nephrolithotomy [4,5\&6]. Others compare the analgesic efficacy of PVB versus epidural block in nephrectomy and intravenous patient controlled analgesia $[7,8]$.

Dexmedetomidine is strong $\alpha 2$ agonist receptors. It poses a greater affinity for $\alpha 2$ adrenergic receptors nearly eight folds greater than clonidine [9]. Recently it had been used widely in regional anesthesia .Owing to its faster onset of action, prolonged duration of analgesia, rapid occurrence of motor and sensory blockade, dose sparing action of local anesthetics and stable hemodynamic variables it was used as a sole adjuvant in regional anesthesia [10]. Efficacy of analgesic effect of dexmedetomidine had been extensively studied in breast cancer surgery $[11,12]$. However, to the best of our knowledge only one study used dexmedetomidine in PVB in renal patients [13].

Therefore, this study was conducted to test the hypothesis that the dexmedetomidine when added to Bupivacaine in paravertebral block for different renal surgeries could enhance the duration of perioperative analgesia with minimal hemodynamic compromise if compared to bupivacaine - fentanyl mixture. 


\section{Methodology}

This randomized, prospective, double- blinded study was conducted on fifty patients subjected to open unilateral renal surgeries (nephrectomy, pyelolithotomy and pyeloplasty) in Urology and Nephrology Center from September 2013 to May 2014. Patients were ASA class I, II of either sex, aged above 20 were recruited in the study. Informed written consent was obtained after obtaining the approval from the local ethical committee in faculty of Medicine, Mansoura University code (MS/265).

Exclusion criteria included patient refusal, infection, sepsis at the puncture site, any coagulation abnormalities, psychiatric diseases, spinal deformity, diabetes mellitus, body mass index $>30 \mathrm{~kg} / \mathrm{m}$ and allergy to any drug used in the study.

Before surgery all patients were assessed by history, physical examination, ECG and full laboratory investigations. The night before surgery the patients had been familiar with the usage of visual analogue score (VAS) $10-\mathrm{cm}$ with 0 means no pain and the 10 means the worst imaginable pain.10mg diazepam was administrated orally.

Eligible patients were randomly allocated by the computer generated list of random permutation into 2 equal groups (each group had 25patient). The randomization according to the anesthetic drugs used in PVB. All personnel providing patient care, the administrator and the patients were blinded to the anesthetic solution used.

\section{Patients in Bupivacaine - Dexmedetomidine(BD)group}

Receive paravertebral Bupivacaine 0.2\% + dexmedetomidine $1 \mu / \mathrm{kg}$ for patient below 65 years and $0.5 \mu / \mathrm{kg}$ for patient above 65 years in a total volume of $20 \mathrm{ml}$.

\section{Patients in Bupivacaine - Fentanyl(BF)group}

Received paravertebral bupivacaine $0.2 \%+$ fentanyl $1 \mu / \mathrm{kg}$ for patient below 65 years and fentanyl $0.5 \mu / \mathrm{kg}$ for patient above 65 years in a total volume of $20 \mathrm{ml}$.

On arrival to the operative theater, the patients connected to the routine monitoring (ECG, NIBP, heart rate, pulse oximetry). An 18 G cannula was inserted and lactated Ringer solution was given at $8 \mathrm{ml} / \mathrm{kg}$.

Patient sit with the back, neck flexed and the shoulders relaxed forward. Under complete aseptic, the spinous process of T10 was palpated and marked on the proposed side of operation. We placed a skin wheal of lidocaine $2 \%$ at T10 and then an 18-gauge short beveled Touhy needle (Perifix, Braun, Melsungeen, Germany) was inserted $2.5 \mathrm{~cm}$ laterally to the upper border of spinous process of T10. The needle was introduced through the skin wheal; according to Eason \& Waytt technique (14) advanced anteriorly perpendicular to the back till it contacts the transverse process, the shaft was grasped with fingers $1 \mathrm{~cm}$ from the skin surface. The fingers serve as a 'backstop' to prevent the passage of the needle $1 \mathrm{~cm}$ into paravertebral space and possibly into the pleura of the lung. Then the tip of the needle withdrawn to the subcutaneous tissue and angles it to 'walk off ' the caudal edge of the transverse process, advancing no more than $1 \mathrm{~cm}$ in to the space. Often loss of resistance or 'pop' is appreciated, indicating the penetration of the costo-transverse ligament. Prior to injection of the anesthetic solution negative aspiration for blood, air or C.S.F had done. Sensory level was tested by pin prick test and ice pack.

General anesthesia was induced by propofol fentanyl I.V. and rocuronium bromide to facilitate intubation. Patients were then mechanically ventilated with tidal volume $(6-8 \mathrm{ml} /$ $\mathrm{kg}$ ). Maintenance of anesthesia by 1 MAC isoflurane, $60 \%$ air in oxygen mixture and top up dose of rocuronium. The residual neuromuscular blockade was reversed with $0.4 \mathrm{mg} / \mathrm{kg}$ neostigmine with $0.2 \mathrm{mg} / \mathrm{kg}$ atropine. Operations were performed by senior staffs in urology and nephrology center.

In PACU, the patients were continuously monitored for 24 hours. The occurrence of postoperative hypotension (defined as decrease systolic arterial pressure by $20 \%$ from the basal). It was treated by I.V. fluids and or boluses of ephedrine $0.1 \mathrm{mg} /$ $\mathrm{kg}$. Bradycardia (defined as heart rate below 50 beats/ min), If happened, it was treated by atropine $0.01 \mathrm{mg} / \mathrm{kg}$. Any adverse effects like pleural puncture, epidural spread, shivering or respiratory distress were reported and treated. Postoperative nausea and vomiting (PONV) were treated with $10 \mathrm{mg}$ metoclopramide I V.

Heart rate (HR),Spo 2 and mean arterial blood pressure were monitored as preoperative (basal), during skin incision, $15 \mathrm{~min}$, $30 \mathrm{~min}, 45 \mathrm{~min}, 1 \mathrm{~h}, 1.5 \mathrm{~h}, 2 \mathrm{~h}, 2.5 \mathrm{~h}, 3 \mathrm{~h}, 4 \mathrm{~h}$ from start of the surgery. Then at $1 \mathrm{~h}, 6 \mathrm{~h}, 12 \mathrm{~h}, 18 \mathrm{~h}$ and $24 \mathrm{~h}$ postoperatively. Pain was assessed using (VAS) recorded at 2, 4,8,12, 24h post-operatively. When the patients experienced (VAS $>3$ ) I.V. meperidine was given in a dose of $50 \mathrm{mg}$ intramuscular and if still VAS more than 3 repeat the dose after $15 \mathrm{~min}$. The total doses of meperidine was recorded. The time of first request of analgesia was recorded. Any postoperative events like nausea, vomiting, shivering or respiratory distress were recorded. Observer's assessment of alertness \& sedation (OAA/S) (15) was used to assess postoperative sedation.

\section{Sample Size Calculation}

A Priori G-power analysis was done to estimate study sample size. A power of $80 \%$ was estimated with type I error of 0.05 to get an analgesic difference between groups of approximately $50 \%$ to yield of total sample size of 45 cases. A drop out of $5 \%$ of cases was expected. Therefore, a total number of 50 cases were needed (25 cases per group).

\section{Statistical Analysis}

This was done by using Statistical Package for Social Science (SPSS, Inc, Chicago, IL, USA) program version 16. To test the normality of data distribution Kolmogorov- Smirnov test was done. Unpaired student-t test was used to compare numerical data between groups. Non-parametric; the Mann-Whitney test was used. Describe the quantitative data in the form of mean $( \pm$ SD), but for qualitative data frequency and proportion was used. Chi square test was used for qualitative data. A (P) value $<0.05$ was considered statistically significant at confidence interval 95\%. 


\section{Results}

Fifty patients underwent different open renal surgeries in Urology and Nephrology center from September 2013 to May 2014, were enrolled in this study. The patients were divided into two equal groups according to the anesthetic solution used in PVB. There was no significant difference found regarding age, sex, body weight, or duration of surgery between both groups (Table 1).

Table1: Demographic data and duration of surgery in both groups. Data are expressed as mean \pm SD.

\begin{tabular}{|c|c|c|c|}
\hline & BF GROUP (n=25) & BD Group(n=25) \\
\hline Age(years) & $53.48 \pm 6.5$ & $54.76 \pm 9.59$ \\
\hline weight(Kg) & $86.3 \pm 11.9$ & $82.6 \pm 14.0$ \\
\hline Sex(M/F) & $14 / 11$ & $11 / 14$ \\
\hline uration of surgery (hours) & $2.86 \pm 0.621$ & 0.3 \\
\hline
\end{tabular}

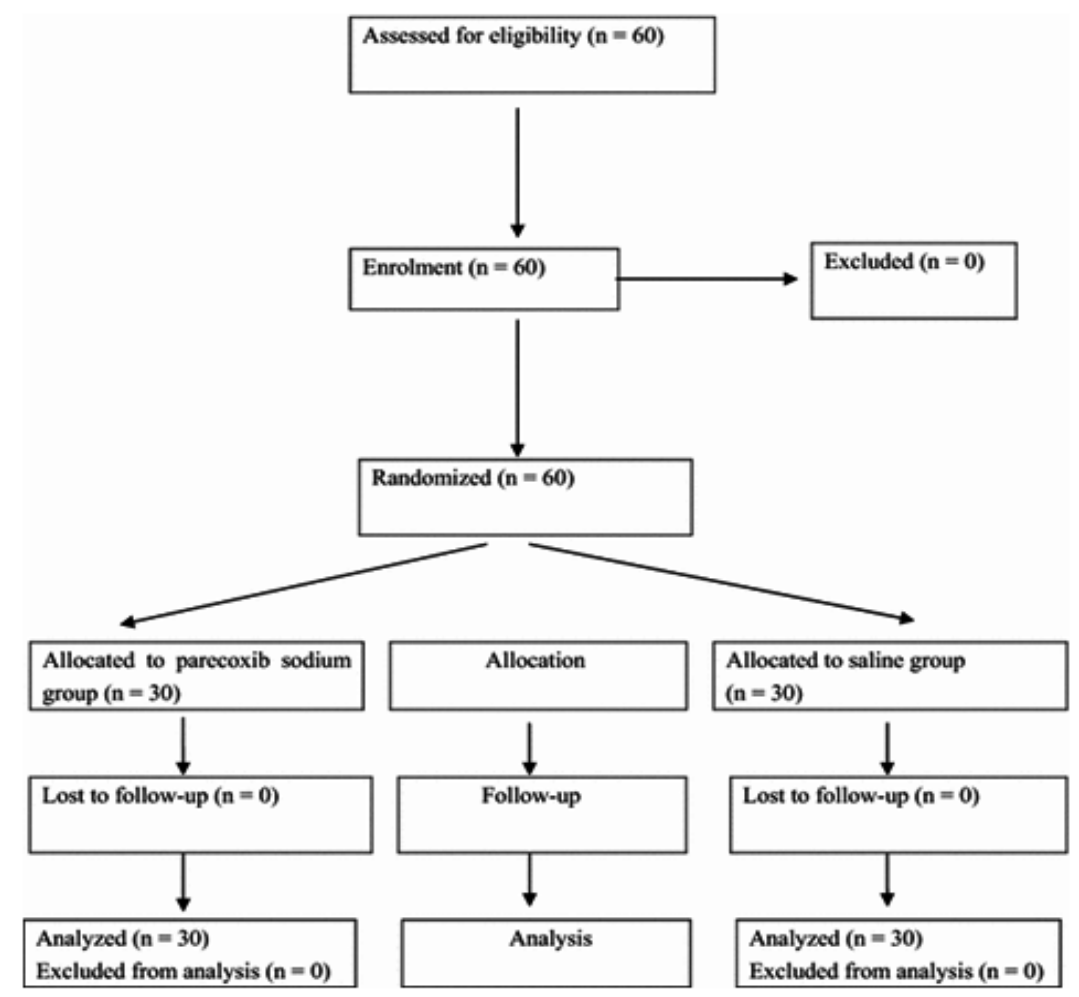

Figure 1: Consort form

There was no statistically significant decrease in intraoperative and postoperative heart rate between both groups except the reading at $2.5 \mathrm{hr}$ where the HR in BD group72.2 \pm 12.8 and in BF 79.3 \pm 8.3 with p value 0.03 (Table 2).

The changes in mean arterial blood pressure were not significantly different between both groups except at $45 \mathrm{~min}, 1 \mathrm{~h}$, $2 \mathrm{~h}$ and $2.5 \mathrm{~h}$ during intra-operative reading where it was lower in BD group than BF group (figure 2).
Peripheral arterial oxygen saturation displayed no significant difference between the studied groups in all reading (Table 3).

Post-operative visual analogue score readings were significantly different between both groups at 2, 4, 8, 12, 24 hours in favor of BD group. (P-value range $=0.001-0.008$ ) (Table 4 , figure 3 ). 
The Effects of Paravertebral Bupivacaine-Dexmedetomidine Versus Bupivacaine-

Copyright: Fentanyl in Unilateral Open Renal Surgeries

Table2: Heart rate in both groups. Data are expressed as mean \pm SD

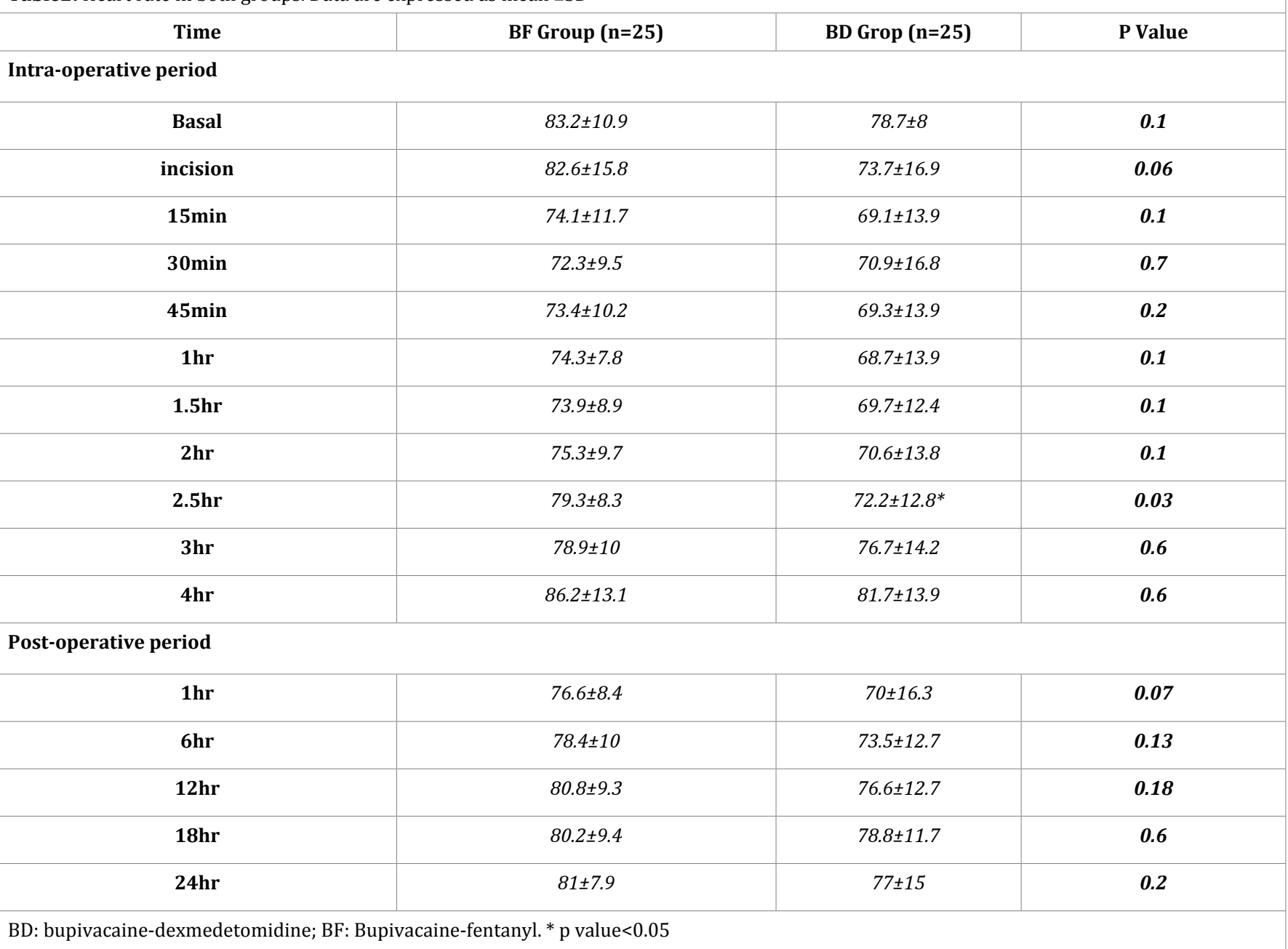

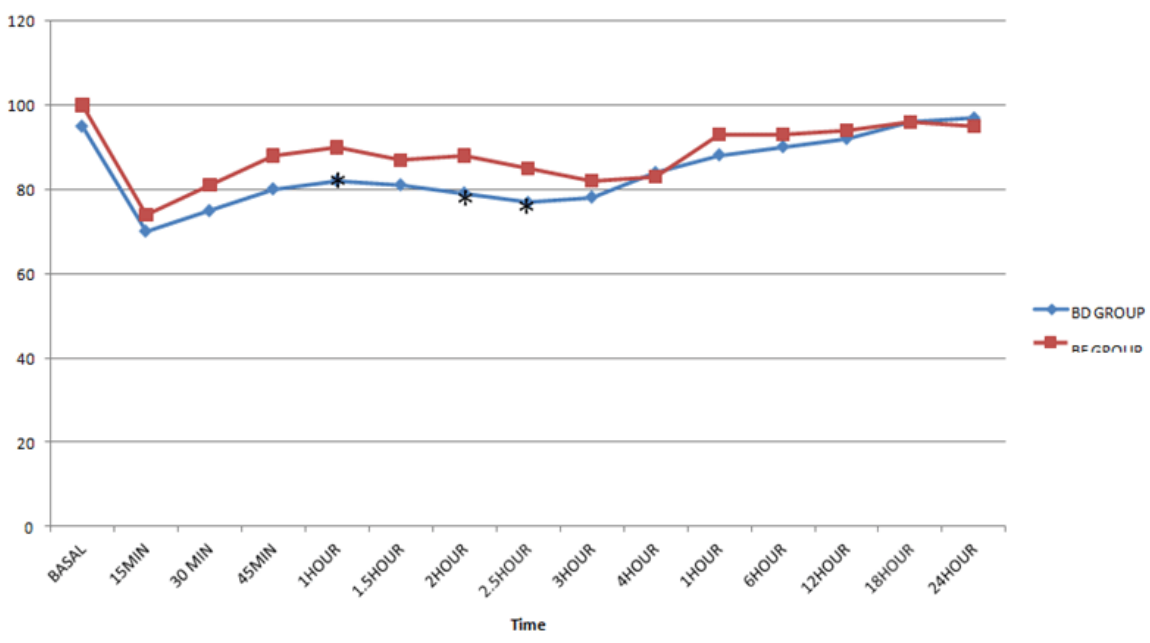

Figure 2: Mean arterial blood pressure in studied group 
The Effects of Paravertebral Bupivacaine-Dexmedetomidine Versus Bupivacaine-

Table 3: perioperative peripheral arterial oxygen saturation data in both groups.

\begin{tabular}{|c|c|c|c|}
\hline Time & BF Group $(n=25)$ & BD Group (n=25) & $P$ value \\
\hline \multicolumn{4}{|c|}{ Intraoperative period } \\
\hline Basal & $99.2 \pm 1.3$ & $99.5 \pm 0.7$ & 0.3 \\
\hline incision & $98.7 \pm 1.4$ & $99 \pm 1.4$ & 0.5 \\
\hline $15 \mathrm{~min}$ & $98.7 \pm 1.5$ & $99.08 \pm 1.2$ & 0.4 \\
\hline 30min & $98.8 \pm 1.2$ & $96.2 \pm 13.8$ & 0.3 \\
\hline $45 \mathrm{~min}$ & $98.9 \pm 1.1$ & $98.5 \pm 1.1$ & 0.2 \\
\hline $1 \mathrm{hr}$ & $98.8 \pm 1.2$ & $98.8 \pm 1.1$ & 0.8 \\
\hline $1.5 \mathrm{hr}$ & $99.2 \pm 0.9$ & $98.9 \pm 1.2$ & 0.3 \\
\hline $2 \mathrm{hr}$ & $99.1 \pm 1.1$ & $99.2 \pm 1.01$ & 0.8 \\
\hline $2.5 \mathrm{hr}$ & $99 \pm 1.01$ & $99.23 \pm 0.9$ & 0.6 \\
\hline $3 \mathrm{hr}$ & $99.1 \pm 0.7$ & $98.9 \pm 1.1$ & 0.5 \\
\hline $4 \mathrm{hr}$ & $99 \pm 1.4$ & $98.9 \pm 1.1$ & 0.7 \\
\hline \multicolumn{4}{|c|}{ Post-operative period } \\
\hline $1 \mathrm{hr}$ & $99.4 \pm 1.4$ & $99.4 \pm 1.3$ & 0.8 \\
\hline $6 \mathrm{hr}$ & $99 \pm 1.4$ & $98.7 \pm 1.6$ & 0.4 \\
\hline $12 \mathrm{hr}$ & $98.7 \pm 1.6$ & $98.4 \pm 1.9$ & 0.5 \\
\hline $18 \mathrm{hr}$ & $98.3 \pm 1.8$ & $98 \pm 1.7$ & 0.5 \\
\hline $24 \mathrm{hr}$ & $98 \pm 2.3$ & $97.9 \pm 1.8$ & 0.8 \\
\hline
\end{tabular}

Table4: Post-operative visual analogue score in the two studied groups. Data expressed as median IQR).

\begin{tabular}{|c|c|c|c|}
\hline Time (hour) & BF Group (n=25) & BD Group (n=25) & P value \\
\hline $\mathbf{2 h}$ & $5(3.5-6)$ & $2(2-4)^{*}$ & $\mathbf{0 . 0 0 2}$ \\
\hline $\mathbf{4 h}$ & $5(3-6)$ & $3(2-5)^{*}$ & $\mathbf{0 . 0 0 8}$ \\
\hline $\mathbf{8 h}$ & $6(5-7)$ & $3(3-4)^{*}$ & $<\mathbf{0 . 0 0 1}$ \\
\hline $\mathbf{1 2 h}$ & $6(5-6)$ & $4(3-5)^{*}$ & $\mathbf{0 . 0 0 6}$ \\
\hline $\mathbf{2 4 h}$ & $6(6-7)$ & $4(3-5)^{*}$ & $<\mathbf{0 . 0 0 1}$ \\
\hline
\end{tabular}

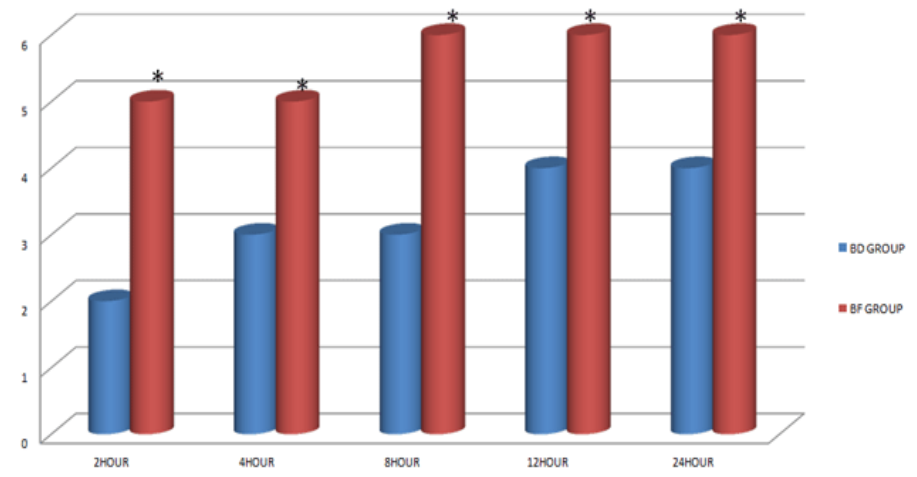

Figure 3: Visual analogue score in studied group. 
As shown in table 5, we found a significant difference between both groups regarding post-operative sedation and alertness score with median score of 3 for BD group versus 4 for BF group ( $p$ - value0.004)

Also in table 5 there were $\mathrm{s}$ a significant difference between both groups regarding the need for postoperative analgesia in favors of BD group. As 4 (16\%) patients in the BD group and 14
(56\%) patients in BF group required postoperative meperidine (p-value0.027).

Duration of analgesia calculated in all patients as the time from the recovery of general anesthesia to the first request for analgesia. The duration of analgesia was found significantly longer in $\mathrm{BD}$ group $(8 \mathrm{H}$ vs $2 \mathrm{H}$ in $\mathrm{BD}$ and $\mathrm{BF}$ groups respectively) (Table 5).

Table5: Alert sedation score, analgesic rescue, duration of post -operative analgesia and post-operative complication.

\begin{tabular}{|c|c|c|c|}
\hline & BF Group(n=25) & BD Group(n=25) & $3.0(3-4)^{*}$ \\
\hline Alert sedation score & $4.00(4-4.50)$ & $\mathrm{N}=4 / 25(16 \%)^{*}$ \\
\hline $\begin{array}{c}\text { No. of patients required post-op. meperdine } \\
\text { Duration of post-op. analgesia in hours } \\
\text { (VAS<3) }\end{array}$ & $\mathrm{N}=14 / 25(56 \%)$ & $8.00(2-12)^{*}$ \\
\hline Post-op nausea \&vomiting. & $\mathbf{0 . 0 2 7}$ & $\mathrm{N}=2 / 25(8 \%)$ \\
\hline Respiratory distress & $\mathrm{N}=1 / 25(4 \%)$ & $\mathbf{0 . 0 1 6}$ \\
\hline
\end{tabular}

VAS: visual analogue score; N: number of patients; post-op: post-operative; BD: bupivacaine- dexmedetomidine; BF: Bupivacaine-fentanyl; Data expressed as median(IQR). ( $\left.{ }^{*}\right)$ Significant inter group difference.

\section{Discussion}

Dexmedetomidine had been extensively used as analgesic adjuvant in many techniques for postoperative analgesia including, subarachnoid, epidural block, caudal and brachial plexus [10\&16-18]. However, few studies had used dexmedetomidine in renal surgeries. The primary outcome was the addition of dexmedetomidine to bupivacaine had a superior analgesic effect than the bupivacaine fentanyl solution alone in patients underwent unilateral renal surgery. Moreover, the addition of dexmedetomidine reduces the postoperative pain score and decreases the needs for postoperative analgesia with lengthening the duration of postoperative analgesia.

The Post- operative visual analogue score was significantly lower in BD group when compared to BF group at all readings. The same results by Sinha S et al, who studied the analgesic profile of $1 \mu \mathrm{g} / \mathrm{kg}$ dexmedetomidine when added to ropivacaine against ropivacaine alone in paravertebral block in patients scheduled for unilateral renal surgery [13]. Also, the same result was demonstrated by Bajwa et al, who found that either addition of $1.5 \mu \mathrm{g} / \mathrm{kg}$ dexmedetomidine or $2 \mu \mathrm{g} / \mathrm{kg}$ clonidine as adjuvant drug to ropivacaine during epidural analgesia had a beneficial effects in the duration of analgesia and the sedation level [17]. The same finding was obtained by Gupta et al, who compared the analgesic effects of $5 \mathrm{mcg}$ of dexmedetomidine against $25 \mathrm{mcg}$ fentanyl when added to $12.5 \mathrm{mg}$ hyperbaric bupivacaine in lower abdominal surgeries [16]. Also EL Hennawy et al, when added dexmedetomidine to caudal Bupivacaine [10]. They found that dexmedetomidine promots the analgesic time with median 16(14-18) against bupivacaine alone median 5(4-6). This could be explained by that dexamedetomidine had both peripheral and central analgesic effects. The central analgesic effects by activation of alpha-2 receptors in locus coeruleus and decrease the release of substance $P$ at the dorsal root neuron. The peripheral analgesic effect by decrease the release of norepinephrine through alpha 2 agonist [19].

In our study, we found that the hemodynamic variables were stable in both studied groups. Although dexamedetomidine has hypotensive and bradycardic effects due to its sympatholytic effects. Richardson explained the hemodynamic stability due to the unilateral blockade of several dermatomes without symathicolysis by PVB effects [20]. Baik considered that the hemodynamic stability was the evidence of a successful block [8]. But Mohta et al when added dexmedetomidine to bupivacaine in patient undergoing radical mastectomy [12]. He found that the PVB with dexmedetomidine is more hemodynamically stable than bupivacaine alone or sham block. This most probably due to stimulation of the presynaptic $\alpha-2$ receptors, so decreasing the release of norepinephrine, resulting in decrease in heart rate and blood pressure [21,22].

The number of patients needed post-operative meperidine was statistically different between the two studied groups as 4 patients (16\%) in BD group versus 14 patients (56\%) in BF group needed meperdine post-operatively. Moreover, the analgesic time was significantly longer in BD gp $8 \mathrm{~h}$ but only $2 \mathrm{~h}$ in BF gp. This was in agreement with Saadawy et al, who found that the addition of dexmedetomidine $1 \mathrm{mg} / \mathrm{kg}$ to bupivacaine $2.5 \mathrm{mg} / \mathrm{ml}(1 \mathrm{ml} /$ $\mathrm{kg}$ ) significantly improved the efficacy of caudal analgesia with less use of post- operative analgesics [23]. This may explained by activation of $\alpha$-2a receptors, inhibition of the conduction of nerve signals through $\mathrm{C}$ and $\mathrm{A} \delta$ fibers and the local release of encephalin.

The study found that the incidence of postoperative nausea and vomiting was comparable with the previous studies This is probably related to the little opioid administered [24,25]. In our 
study no patients had respiratory distress in the post-operative period. This result passes in agreement with previous studies. This could be attributed to the type of patients selected in this study. One of the great benefits of dexmetedomidine in renal patients that, it is metabolized in the liver into inactive metabolites and its elimination not affected with kidney. So, dexmetedomidine offers an alternative option for renal analgesia.

\section{Conclusion}

Addition of dexmedetomidine to preoperative paravertebral block improves the analgesic profile by decreasing VAS and analgesic requirement with increase the duration of analgesia and hemodynamic stability in patients underwent open renal surgeries.

\section{Limitation of the study}

The main limitation of this study is doing the block blindly .The usage of ultrasound guided blockade will further enhance the performance of the block. Also one of the potential study design drawbacks is the short duration of postoperative follow up for analgesia. We recommend further study including long time of follow up for at least $48 \mathrm{hs}$ postoperatively.

\section{Conflict of interest}

The authors declare no conflict of interest.

\section{References}

1. Kararmaz A, Kaya S, Karaman H, Turhanoglu S and Ozyilmaz MA. Intraoperative intravenous ketamine in combination with epidural analgesia: postoperative analgesia after renal surgery. Anesth Analg. 2003;97(4):1092-1096.

2. Shoeibi G, Babakhani B and Mohammadi SS. The efficacy of ilioinguinal-iliohypogastric andintercostal nerve co-blockade for postoperative pain relief in kidney recipients. Anesth Analg. 2009;108(1):330-333.

3. Davies RG, Myles PS and Graham JM. A comparison of the analgesic efficacy and side-effects of paravertebral vs epidural blockade for thoracotomy-a systemic review and meta-analysis of randomized trials. Br J Anaesth 2006;96(4);418-26.

4. Hanoura S, Elsayed M, Eldegwy M, Ahmed Elsayed, Tamer Ewieda and Shehab M. Paravertebral block is a proper alternative anesthesia for outpatient lithotripsy. Anesth Essays Res. 2013;7(3):365-370. Doi: 10.4103/0259-1162.123238.

5. Dubut J, Kastler B, Delabrousse E, Nardin C, Chenet J and Kleinclauss. et al. C T -guided PVB for microwave ablation of kidney tumors: a new technique. Abdom Radiol 2016;41(6):1197-1202. Doi: 10.1007/ s00261-016-0738-3.

6. Ak K, Gursoy S, Duger C, IsbirAC, Kaygusuz K and Ozdemir Kol L. et al. Thoracic paravertebral block for postoperative pain management in percutaneous nephrolithotomy patients: a randomized controlled clinical trial. Med Princ Pract. 2013;22(3):229-233. Doi: 10.1159/000345381.
7. Moawad HE, Mousa SA and EL Hefnawy AS. Single dose paravertebral block versus epidural blockade for pain relief after open renal surgery: A prospective randomized study. Saudi J Anaesth .2013;7(1):61-67. Doi: 10.4103/1658-354X.109814.

8. Baik JS, Oh AY, Cho CW, Shin HJ, Han SH and Ryu JH. Thoracic paravertebral block for nephrectomy .a randomized, controlled, observer-blinded study .Pain Med 2014 May;15(5);850-6. Doi: 10.1111/pme.12320.

9. Konakci S, Adanir T, Yilmaz G, Rezanko T. The efficacy and neurotoxicity of dexmedetomidine administered via the epidural route. Eur J Anaesthesiol 2008, 25(5):403-9. Doi: 10.1017/ S0265021507003079.

10.El-Hennawy AM, Abd-Elwahab AM, Abd-Elmaksoud AM, El Ozairy HS and Boulis SR. Addition of clonidine or dexmedetomidine to bupivacaine prolongs caudal analgesia in children. Br J Anaesth. 2009;103(2):268-274. Doi: 10.1093/bja/aep159.

11. Mohamed SA, Fares KM, Mohamed AA and Alieldinn NH. Dexmedetomidine as an adjunctive analgesic with bupivacaine in paravertebral analgesia for breast cancer surgery. Pain Physician.2014;17(5):E589-98.

12. Mohta M, Kalra B, Sethi AK and Kaur N. Efficacy of dexmedetomidine as an adjunvant in paravertebral block in breast cancer surgery .J Anesth. 2016;30(2):252-260. Doi: 10.1007/s00540-015-2123-8.

13.Sinha S, Mukherjee M, Sajib Chatterjee, Mukesh K Vijay, Abhijit Hazra and Manjushree Ray. Comparative study of analgesic efficacy of ropivacaine with ropivacaine plus dexmedetomidine for paravertebral block in unilateral renal surgery. Anesth Pain Intensive Care 2012;16(1):38-42.

14. Eason MJ and Wyatt R. Paravertebral thoracic block-a reappraisal. Anaesthesia. 1979;34(7):638-642.

15.Ravinder Kumar Batra, Krithika Krishnan and Agarwal A. Paravertebral Block: review article. J Anaesthesiol Clin Pharmacol. 2011;27(1):5-11.

16. Gupta R, Verma R, Bogra J, Monica K, Rajesh R and Jitendra Kumar K. Acomparative study of intrathecal dexmedetomidine and fentanyl as adjuvants to bupivacaine .J Anaesthesiol Clin Pharmacol. 2011;27:339-343. Doi: 10.4103/0970-9185.83678.

17. Bajwa SJ, Bajwa SK, Kaur J, Singh G, Arora V and Gupta S. et al. Dexmedetomidine and clonidine in epidural anaesthesia: A comparative evaluation. Indian J Anaesth. 2011;55(2):116-21. Doi: 10.4103/0019-5049.79883.

18. Esmaoglu A, Yegenoglu F, Akin A and Turk CY. Dexmedetomidine Added to Levobupivacaine Prolongs Axillary Brachial Plexus Block. Anesthesia \& Analgesia. 2010;111(6):1548-1551. Doi: 10.1213/ ANE.0b013e3181fa3095.

19. Biswas S, Das RK,Mukherjee G, Ghose T. Dexmedetomidine as adjuvant to levobupivacaine in supraclavicular brachial plexus block:a randomized double blind prospective study. Ethiop J Health Sci. 2014;24(3):203-208.

20.Richardson J and Lonnqvist PA. Thoracic paravertebral block. Br J Anaesth. 1998;81(2):230-238. 
21. Kamibayashi T and Maze M. Clinical uses of alpha2 -adrenergic agonists. Anesthesiology. 2000;93(5):1345-1349.

22.Penttila J, Helminen A, Anttila M, Hinkka S and Scheinin. Cardiovascular and parasympathetic effects of dexmedetomidine in healthy subjects. Can J Physiol Pharmacol. 2004; 82(5):359-362.

23. Saadawy I, Boker A, Elshahawy MA, Almazrooa A, Melibary S and Abdellatif. et al. Effect of dexmedetomidine on the characteristics of bupivacaine in a caudal block in pediatrics. Acta Anaesthesiol Scand. 2009;53(2):251-256. Doi: 10.1111/j.1399-6576.2008.01818.x.
24.Snijdelaar DG, Hasenbos MA, van Egmond J, Wolff AP and Liem TH. High thoracic epidural sufentanil with bupivacaine: continuous infusion of high volume versus low volume. Anesth Analg. 1994;78(3):490-494.

25. Mourisse J, Hasenbos MA, Gielen MJ, Moll JE and Cromheecke GJE. Epidural bupivacaine, sufentanil or the combination for postthoracotomy pain. Acta Anaesthesiol Scand. 1992,;36(1):70-74. 